Supplementary Information for

\title{
On-surface Synthesis of Thiophane-containing Large-sized Organometallic Macrocycles on Ag(111) Surface
}

Xin Zhang ${ }^{1,5, \#, ~ Q i a n ~ S h e n ~}{ }^{2, \#}$, Haoxuan Ding ${ }^{3, \#, ~ X i a o r u i ~ C h e n ~}{ }^{4}$, Hualin

Yang ${ }^{3}$, Bosheng $\mathrm{Li}^{3}$, Xiu $\mathrm{Liu}^{4}$, Haiping $\mathrm{Lin}^{4}$, Qing $\mathrm{Li}^{4}$, Jianzhi Gao ${ }^{4, *}$,

Gongqiang $\mathrm{Li}^{2, *}$, Minghu Pan ${ }^{4, *}$ and Quanmin $\mathrm{Guo}^{3, *}$

${ }^{1}$ School of Physics, Northwest University, 710069, China

${ }^{2}$ Institute of Advanced Materials, Nanjing Tech University, Nanjing 210009, China

${ }^{3}$ School of Physics and Astronomy, University of Birmingham, Birmingham B15 2TT, United Kingdom

${ }^{4}$ School of Physics and Information Technology, Shaanxi Normal University, Xi'an 710119, China

${ }^{5}$ Shaanxi Key Laboratory for Theoretical Physics Frontiers, 710069, China 


\section{Supplementary STM \& DFT calculation results}
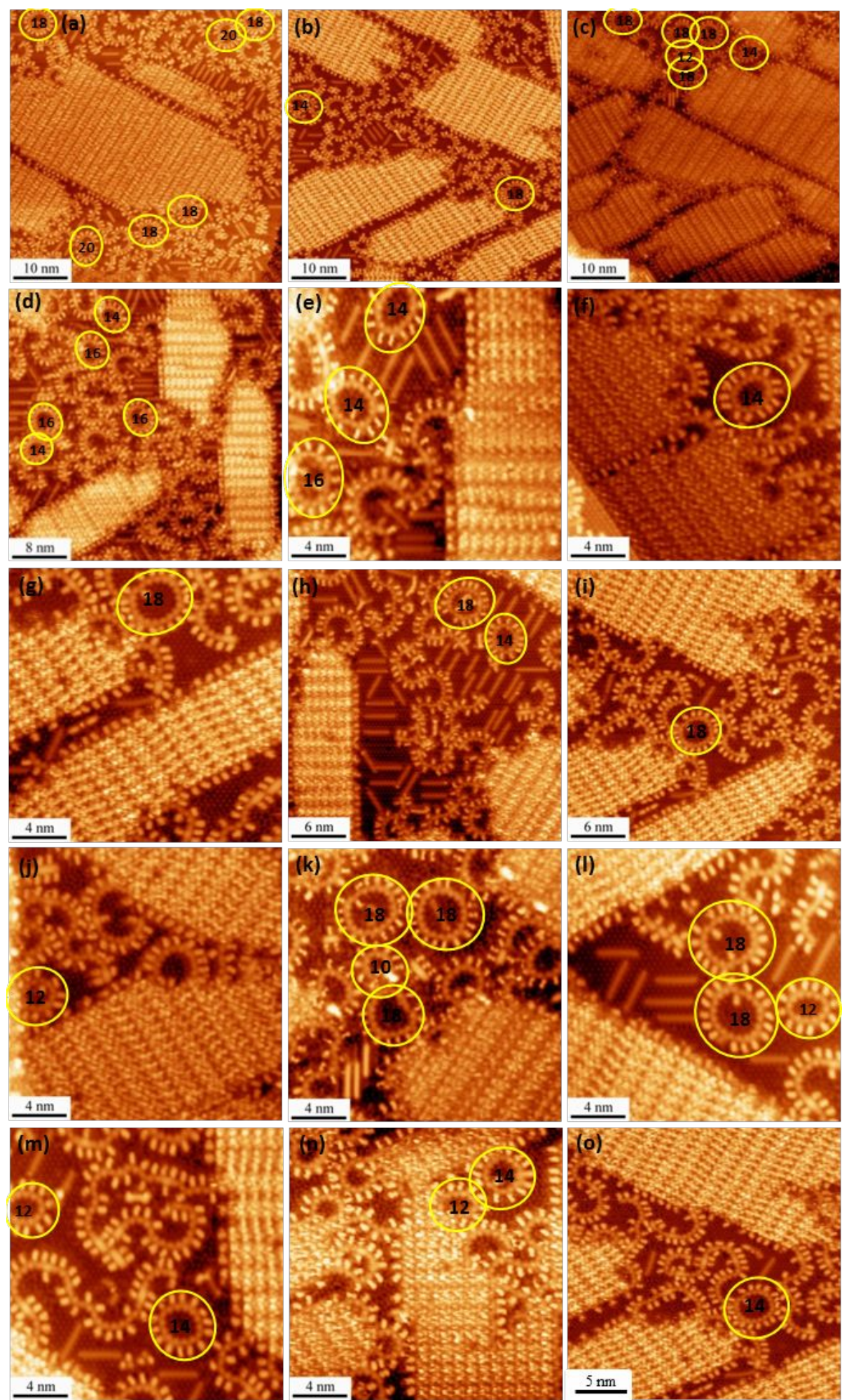

Figure S1. The large-scaled STM images of the reacted products after annealing the sample $(\mathrm{TPD} / \mathrm{Ag}(111))$ at $120{ }^{\circ} \mathrm{C}$ for $10 \mathrm{~min}$. The organometallic rings with the marked sizes are highlighted by yellow circles. 


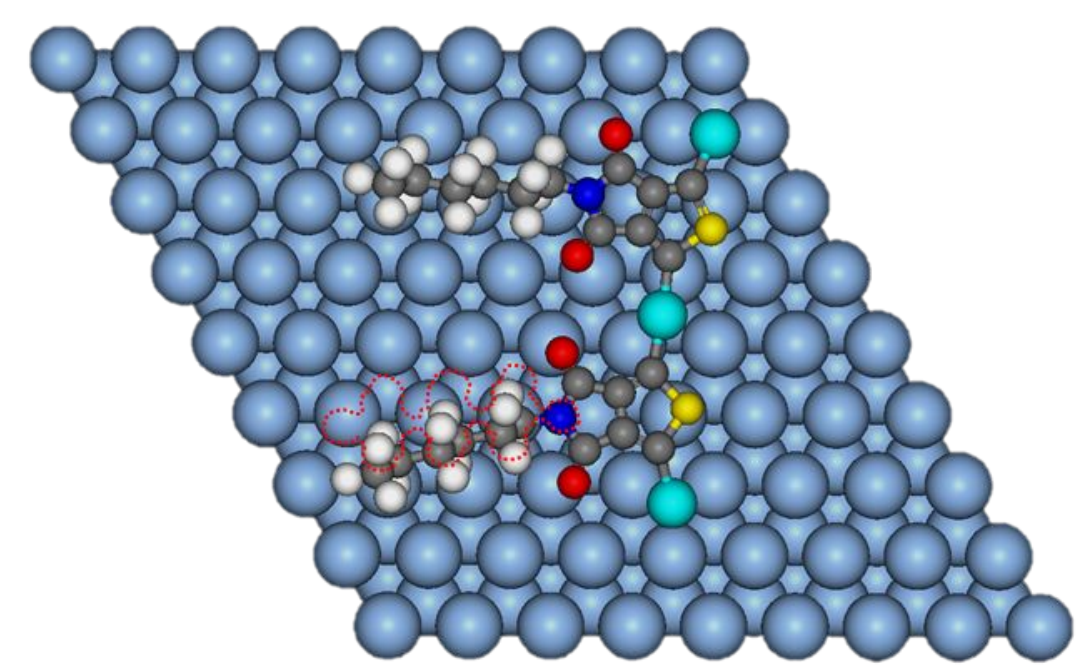

Figure S2. Top view for the optimized adsorption geometry of (DeTPD-Ag) $)_{2}$ dimer on $\operatorname{Ag}(111)$ surface. The red outline shows the original position of the alkyl chain in the individual (DeTPD-Ag) monomer. Tilting is happened for alkyl chain with respect to the molecular backbone under the van der Waals interaction in the dimer.
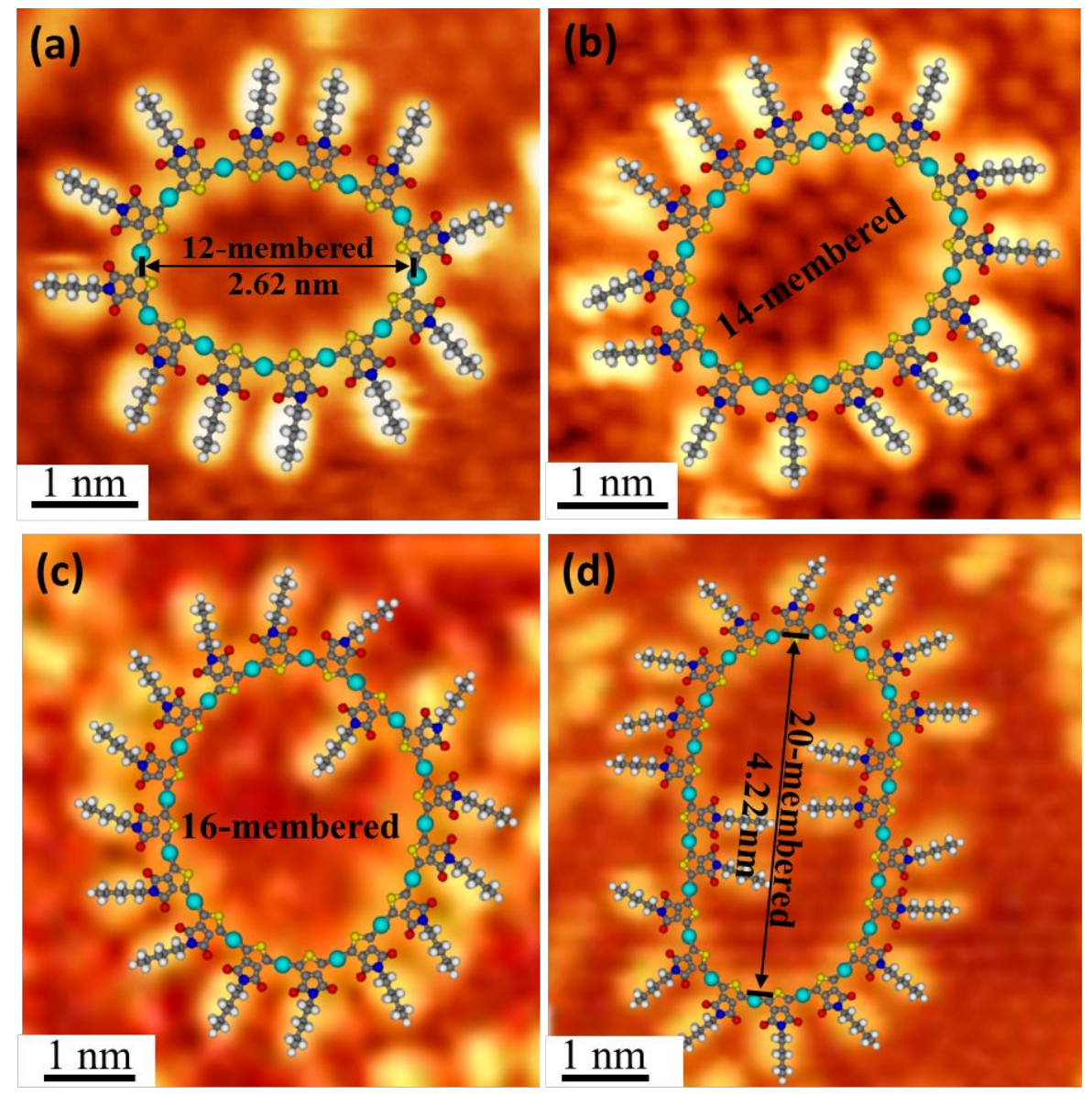

Figure S3. STM images and proposed models of (DeTPD-Ag $)_{n}(n=12$, 14, 16, and 20) rings with the sizes from $2.62 \mathrm{~nm}$ to $4.22 \mathrm{~nm}$ on $\operatorname{Ag}(111)$ 
surface. The sizes are measured along the major axis of oval shapes. These structural models are consistent with the physical size of TPD and features in the STM observation.
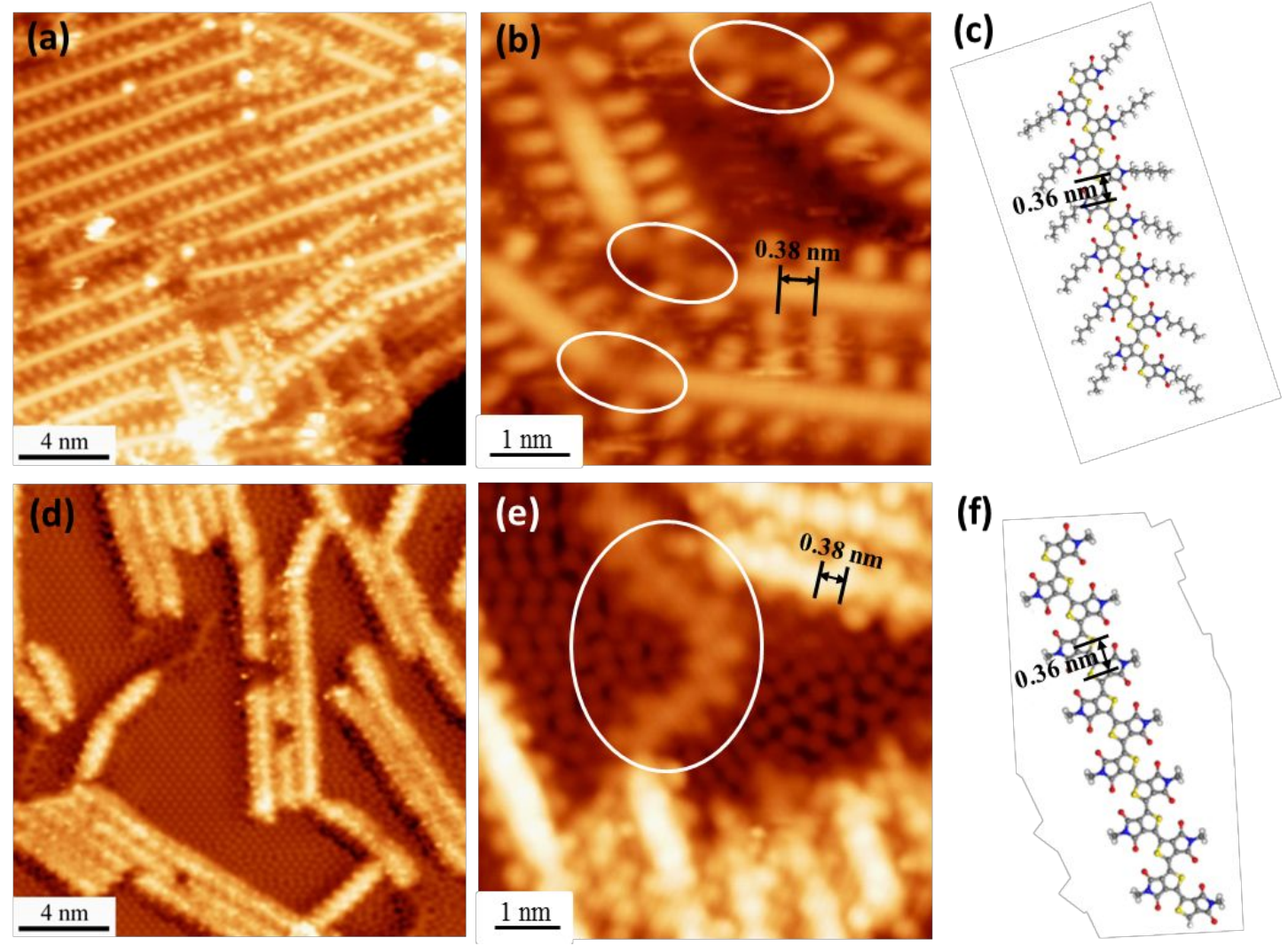

Figure S4. The poly-TPD/Me-TPD chains after annealing at $200{ }^{\circ} \mathrm{C}$ for 10 min. (a), (d) Large scaled STM images of TPD and Me-TPD polymer lines. (b), (e) Magnified view of polymer chains for TPD and Me-TPD molecules. The white cycles highlight partial unreacted organometallic structures. (c), (f) The proposed models of polymer chains. The distance between the adjacent monomers was about $0.38 \mathrm{~nm}$, matches well with the calculated ones $(0.36 \mathrm{~nm})$. 

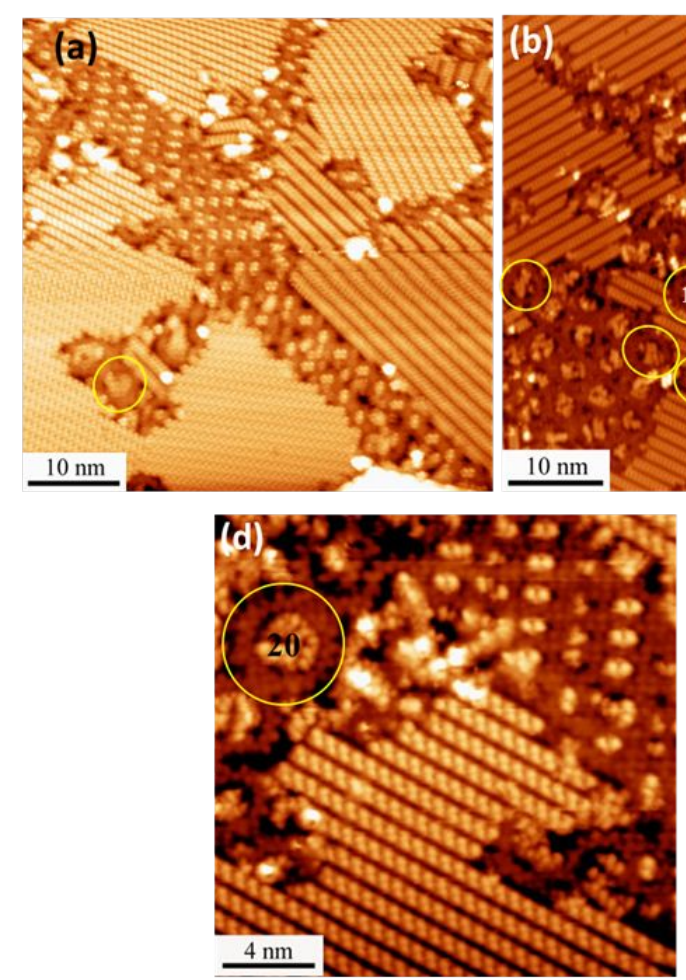

(e)

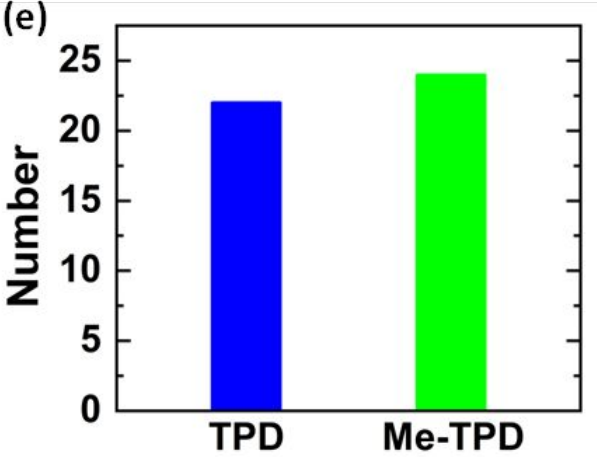

Figure S5. (a)-(d) Large-sized STM images show the reaction products of Me-TPD molecules adsorbed on $\operatorname{Ag}(111)$ surface after annealing the sample at $120^{\circ} \mathrm{C}$ for $10 \mathrm{~min}$. The organometallic rings are highlighted by yellow circles. (e) The histogram gives a comparison of organometallic ring yield for $\mathrm{TPD} / \mathrm{Ag}(111)$ and $\mathrm{Me}-\mathrm{TPD} / \mathrm{Ag}(111)$ systems in the scanning range of $200 \times 200 \mathrm{~nm}^{2}$. 

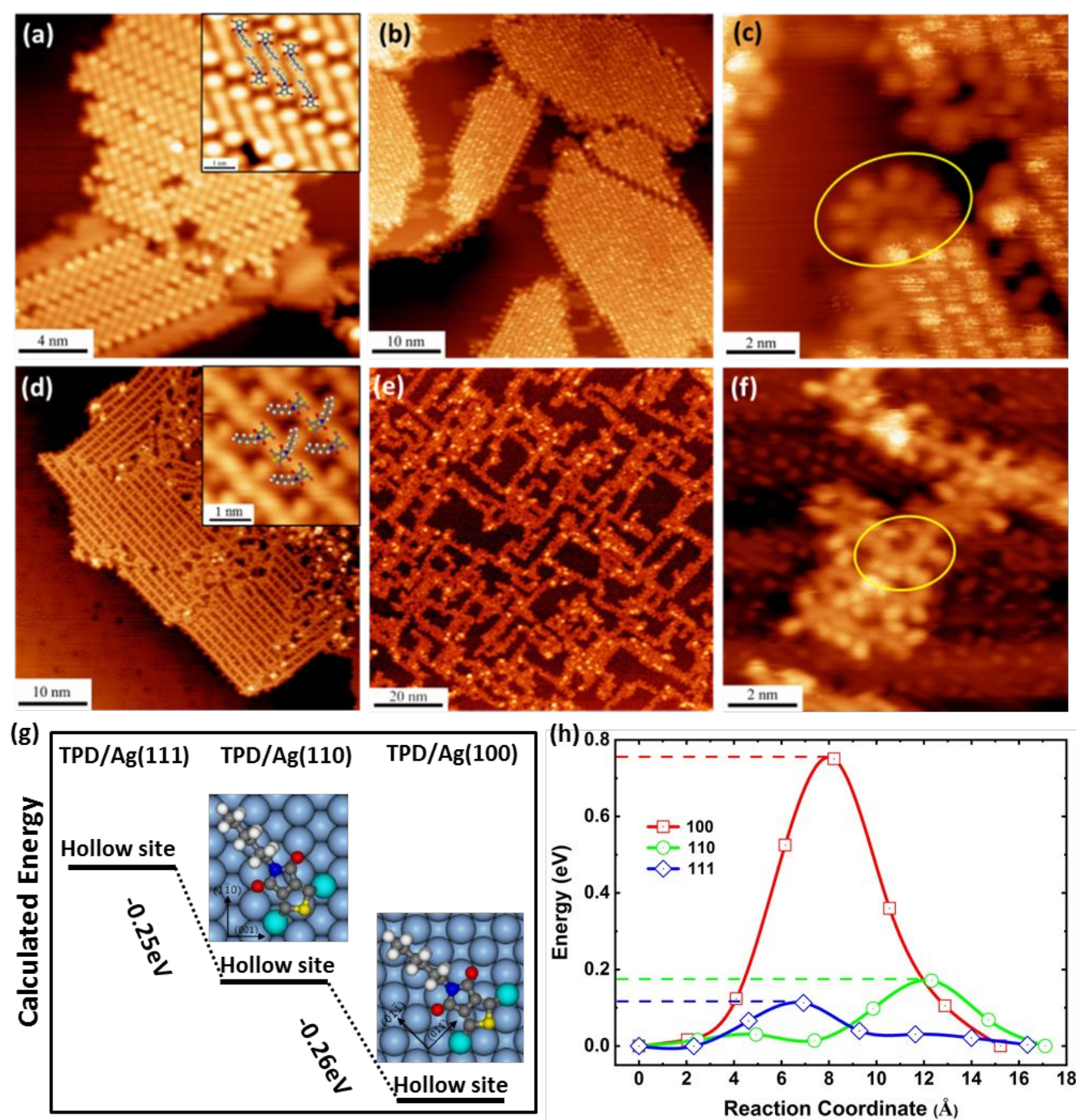

Figure S6. The structural evolution of TPD molecules on $\operatorname{Ag}(110)$ and $\operatorname{Ag}(100)$ surfaces with the on-surface reaction. (a), (d) STM images of the self-assembly structures for TPD molecules on $\operatorname{Ag}(110)$ and $\operatorname{Ag}(100)$ after room temperature deposition, respectively. The proposed molecular arrangements are superimposed on the top of the high resolution STM images in the insets. (b), (e) Large-scaled STM images of the formed structures after annealing the $\operatorname{Ag}(110)$ and $\operatorname{Ag}(100)$ substrates at $150{ }^{\circ} \mathrm{C}$ for $10 \mathrm{~min}$. A few curved structures can be found, showing similar trends as on $\operatorname{Ag}(111)$, while no macrocycle is observed. (c), (f) Enlarged STM images of the curved organometallic structures highlighted by yellow cycles on $\operatorname{Ag}(110)$ and $\operatorname{Ag}(100)$ surfaces, respectively. (g) The difference of the calculated adsorption energies, as well as (h) the nudge elastic band calculations and the diffusion barriers for (TPD-Ag) segments on $\operatorname{Ag}(111), \operatorname{Ag}(110)$ and $\operatorname{Ag}(100)$ surfaces. The (TPD-Ag) segments hold both the smallest adsorption energies and diffusion barriers on $\operatorname{Ag}(111)$ surface. 


\section{Synthetic methods}
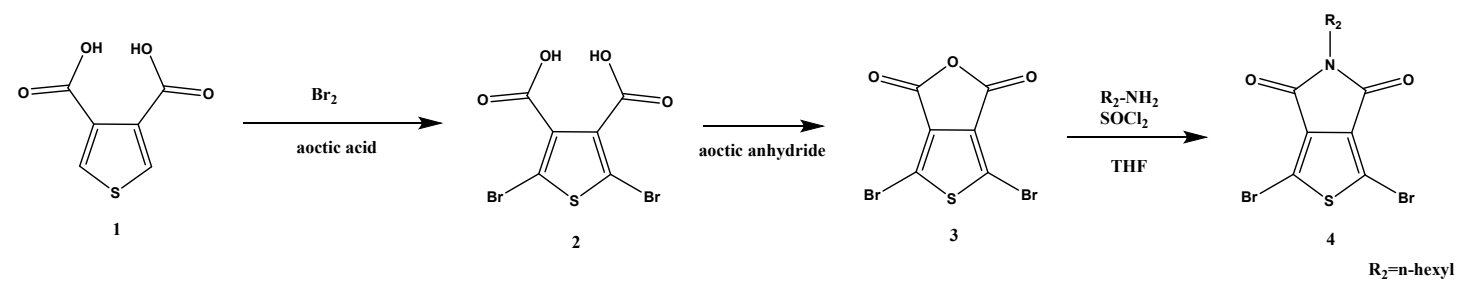

2,5-Dibromothiophene-3,4-dicarboxylic

acid

(2)

and

4,6-Dibromothieno[3,4-c]furan1,3-dione

(3)

were

synthesized

according to previously reported methods. General procedure for the preparation

of

\section{1,3-Dibromo-5-(n-alkyl)-4H-thieno[3,4-c]pyrrole-4,6(5H)-dione}

(TPD): Compound 3 (1.46 g, $4.68 \mathrm{mmol})$ was charged in a $50 \mathrm{~mL}$ flask, dissolved in $12 \mathrm{~mL}$ of dry THF under inert atmosphere, and an n-alkylamine derivative $(4.90 \mathrm{mmol})$ was added at room temperature. Next, the reaction mixture was warmed up to $50{ }^{\circ} \mathrm{C}$ and stirred for $3 \mathrm{~h}$. The mixture was then allowed to cool down to room temperature, and the volatiles were removed in vacuo. Next, thionyl chloride $(5 \mathrm{~mL})$ was added at room temperature to the main flask, and the reaction mixture was warmed up to $55{ }^{\circ} \mathrm{C}$ and stirred for $4 \mathrm{~h}$. The mixture was then allowed to cool down to room temperature, and the reaction contents were added dropwise to a mixture of water $(100 \mathrm{~mL})$ and methanol $(50$ $\mathrm{mL}$ ). The precipitate was filtered off, dried, redissolved in chloroform $\left(\mathrm{CHCl}_{3}\right)$, and purified by column chromatography over silica gel $\left(\mathrm{CHCl}_{3}\right)$, yielding a white powder. The white solid was finally recrystallized from 
ethanol to afford the desired TPD monomers as white flakes.

1,3-Dibromo-5-(n-heptyl)-4H-thieno[3,4-c]pyrrole-4,6(5H)-dione (4): (1.64 g, 86\%) Recrystalized for three times.

$1 \mathrm{H} \mathrm{NMR} \mathrm{(CDCl3,} 400 \mathrm{MHz}): \delta(\mathrm{ppm})=3.58(\mathrm{t}, \mathrm{J}=7.3 \mathrm{~Hz}, 2 \mathrm{H}), 1.64$ (m, 2H), $1.30(\mathrm{~m}, 8 \mathrm{H}), 0.87(\mathrm{t}, \mathrm{J}=6.7 \mathrm{~Hz}, 3 \mathrm{H}) .13 \mathrm{C} \mathrm{NMR}(\mathrm{CDCl} 3,100$ $\mathrm{MHz}): \delta(\mathrm{ppm})=160.21,134.6,112.7,38.6,31.4,28.6,28.1,26.6,22.4$, 13.9. HRMS (+ESI, m/z): calcd. for $\mathrm{C}_{13} \mathrm{H}_{16} \mathrm{Br}_{2} \mathrm{NO}_{2} \mathrm{~S}[\mathrm{M}+\mathrm{H}]+$ : 407.9268; found, 407.9263. Anal. calcd. for $\mathrm{C}_{13} \mathrm{H}_{15} \mathrm{Br}_{2} \mathrm{NO}_{2} \mathrm{~S}$ : C, 38.16; H, 3.10; N, 3.42; S: 7.84; found: C, 38.33; H, 3.66; N, 3.46; S: 7.87 .

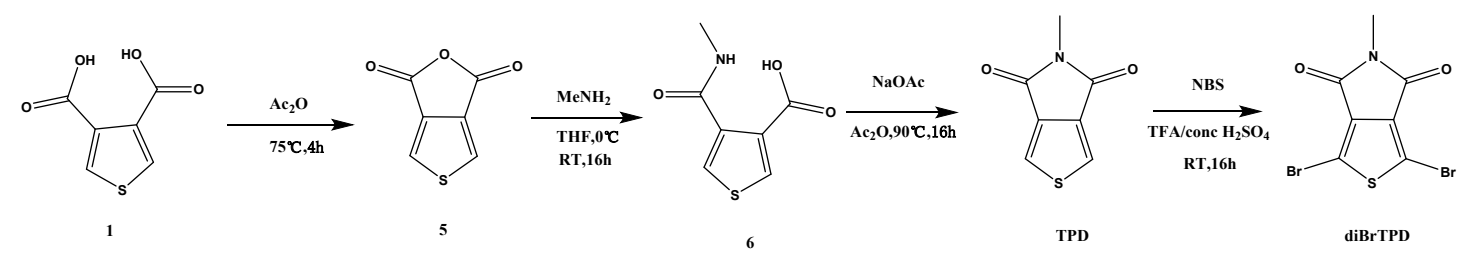

1H,3H-thieno[3,4-c]furan-1,3-dione (2). In a round-bottom flask equipped with a condenser and open to atmosphere, a suspension of thiophene-3,4-dicarboxylic acid (1) $(5.0 \mathrm{~g}, 29.0 \mathrm{mmol})$ in acetic anhydride $(50 \mathrm{~mL})$ was heated at $75{ }^{\circ} \mathrm{C}$ for $4 \mathrm{~h}$. The undissolved residue was filtered off when the reaction mixture was still hot. The solvent was removed by rotary evaporation to afford a brown solid as crude product. The crude product was dissolved in hot toluene and then filtered to remove the undissolved residue. The hot solution was placed in a freezer for recrystallization, which afforded brown needles in $76 \%$ yield. $\mathbf{1 H}$ NMR (500 MHz, CDCl3, $\delta, p p m): 8.12$ (s, 2H). 13C NMR (125 MHz, 
$\mathrm{CDCl} 3, \delta, \mathrm{ppm}): 156.4,135.2,129.4$

4-(methylcarbamoyl)thiophene-3-carboxylic acid (3). In a round-bottom flask with a septum, a solution of $1(4.4 \mathrm{~g}, 28.5 \mathrm{mmol})$ in anhydrous THF $(50 \mathrm{~mL})$ was degassed and filled with nitrogen at $0{ }^{\circ} \mathrm{C}$. Methylamine (19 mL, $33 \mathrm{wt} \%$ in ethanol) was slowly injected into the solution. Precipitate was formed during the addition and dissolved afterwards. The reaction mixture was stirred for $16 \mathrm{~h}$ at room temperature, then transferred dropwise into a flask containing $2 \mathrm{M} \mathrm{HCl}$ $(150 \mathrm{~mL})$ and stirred for $30 \mathrm{~min}$. The precipitate was collected by filtration and dried to afford an off-white solid in $83 \%$ yield.

$1 H$ NMR (500 MHz, DMSO-d6, $\delta$, ppm): 14.30 (s, 1H), 8.93 (d, 1H, J = $3.9 \mathrm{~Hz}), 8.33(\mathrm{~d}, 1 \mathrm{H}, \mathrm{J}=3.4 \mathrm{~Hz}), 8.12(\mathrm{~d}, 1 \mathrm{H}, \mathrm{J}=3.4 \mathrm{~Hz}), 2.79(\mathrm{~d}, 3 \mathrm{H}, \mathrm{J}$ $=4.6 \mathrm{~Hz}) .13 \mathrm{C}$ NMR (125 MHz, DMSO-d6, $\delta, \mathrm{ppm}): 164.6,162.9$, $136.3,135.1,132.8,131.0,26.2$.

5-methyl-4H-thieno[3,4-c]pyrrole-4,6(5H)-dione. In a round-bottom flask equipped with a condenser and open to atmosphere, a mixture of 2 (4.5 g, $24.3 \mathrm{mmol})$ and sodium acetate (199 $\mathrm{mg}, 10 \mathrm{~mol} \%)$ in acetic anhydride $(100 \mathrm{~mL})$ was heated at $90{ }^{\circ} \mathrm{C}$ for $16 \mathrm{~h}$. After being cooled to room temperature, the reaction mixture was added into water $(200 \mathrm{~mL})$ and stirred for $30 \mathrm{~min}$. The precipitate was extracted with dichloromethane and washed with brine. The organic phase was collected and dried over anhydrous magnesium sulfate. The mixture was filtered 
and the solvent was removed by rotary evaporation. The residue was purified by column chromatography on silica, eluting with dichloromethane/ethyl acetate $(10: 1, \mathrm{v} / \mathrm{v})$ to afford a white solid in $93 \%$ yield.

1H NMR (500 MHz, CDCl3, $\delta, \mathrm{ppm}): 7.86$ (s, 2H), 3.12 (s, 3H). 13C

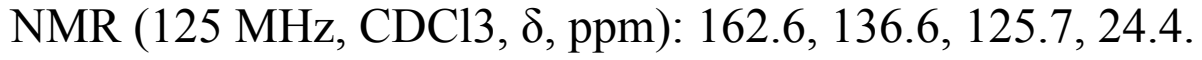

1,3-dibromo-5-methyl-4H-thieno[3,4-c]pyrrole-4,6(5H)-dione. In a round-bottom flask with a stopper, $3(1.5 \mathrm{~g}, 9.0 \mathrm{mmol})$ in trifluoroacetic acid/concentrated sulfuric acid $(3: 1, \mathrm{v} / \mathrm{v}, 8 \mathrm{~mL})$ with the addition of N-bromosuccinimide (4.8 g, $26.9 \mathrm{mmol})$ was stirred at room temperature for $16 \mathrm{~h}$. The reaction mixture was then poured into water $(100 \mathrm{~mL})$. The precipitate was extracted with dichloromethane and washed with brine. The organic phase was collected and dried over anhydrous magnesium sulfate. The mixture was filtered and the solvent was removed. The residue was purified by column chromatography on silica, eluting with hexanes/dichloromethane $(1: 2, \mathrm{v} / \mathrm{v})$ to afford a white solid in $83 \%$ yield, the product was purified by recrystallization for three times with EA/Hexane. 1H NMR (500 MHz, DMSO-d6, $\delta$, ppm): 2.94 (s, 3H). 13C

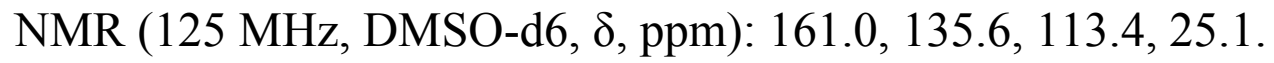

